\section{EREM 77/2}

Journal of Environmental Research, Engineering and Management Vol. 77 / No. 2 / 2021 pp. $37-42$

DOI 10.5755/j01.erem.77.2.25543
Characterization of Acid Impregnated Activated Carbon

Developed from Tannery Sludge

\begin{tabular}{l|l}
\hline Received 2020/03 & Accepted after revision 2021/06 \\
\hline
\end{tabular}

http://dx.doi.org/10.5755/j01.erem.77.2.25543

\title{
Characterization of Acid Impregnated Activated Carbon Developed from Tannery Sludge
}

\section{Geethakarthi Alagarsamy*}

Associate Professor, Department of Civil Engineering, Kumaraguru College of Technology,

Coimbatore - 641 049, Tamilnadu, INDIA

*Corresponding author: geethakarthi.a.ce@kct.ac.in

The sludge discharged from the preliminary treatment of a tannery effluent plant is considered for the development of activated carbon. The carbon is developed by impregnating the precursor in an acid activating agent $\left(\mathrm{H}_{2} \mathrm{SO}_{4}\right)$. The activation of the preliminary sludge is carried under different operating conditions such as varying temperature $\left(600-800^{\circ} \mathrm{C}\right.$ ) and acid impregnation ratios ( 1 and 2) for two different particle sizes such as $600 \mu \mathrm{m}$ and $300 \mu \mathrm{m}$. A carbon content of $74 \%$ was obtained from the sludge activated at a temperature of $650^{\circ} \mathrm{C}$ for $3 \mathrm{hrs}$ with particle size $300 \mu \mathrm{m}$ (3S-52). The characterization of developed tannery sludge carbon 3S-52 was carried out using Scanning Electron Microscopy (SEM) and Brunauer-Emmett-Teller (BET) isotherm plots to analyze the surface morphology and pore size distribution, pore volume and pore diameter. The nitrogen physisorption for surface analysis and pore size distribution was also done at $-196^{\circ} \mathrm{C}(77 \mathrm{~K})$. The pore volume, pore size and the surface area of $3 \mathrm{~S}-52$ were determined as $0.133 \mathrm{~cm}^{3} / \mathrm{g}, 5.15 \mathrm{~A}^{\circ}$ and $212.32 \mathrm{~m}^{2} / \mathrm{g}$ respectively. These results demonstrated feasibility to treat the tannery sludge as a precursor to produce microporous activated carbons.

Keywords: activated carbon, microporous carbon, Scanning Electron Microscopy (SEM), surface area, tannery sludge. 


\section{Introduction}

The most attractive option of sludge management is the sludge minimization and reuse. The necessity of sustainable and safe waste recycling process is indicated in several studies (Anna Ros et al., 2007; Tiecheng Guo et al., 2004). This has led to the preparation of value-added products such as activated carbon. There are several activation methods available to convert industrial sludge into useful sorbents. The physical activation method consists of two basic processes, namely, carbonization and activation. To obtain a rigid matrix, less prone to volatile loss and volume contraction upon heating, chemical reagents were used. The surface area of the activated carbon may be increased by the addition of $\mathrm{KOH}$ and $\mathrm{ZnCl}_{2}$, which are the widely used chemical reagents (Li et al., 2014). The impregnation with chemical activating agent as a catalyst by enhancing the pore sizes and lowering the reaction temperature. The pore size of the activated carbons is generally classified as micropores (less than $2 \mathrm{~nm}$ pore width), mesopores (between $2 \mathrm{~nm}$ and $50 \mathrm{~nm}$ pore width) and macropores (greater than $50 \mathrm{~nm}$ pore width). This research work has primarily focused on the use of tannery sludge, else let as unused waste resource in the production of a cost effective microporous activated carbon. The activated carbon developed from tannery sludge has an increased surface area and pore volume distribution and proved to be an effective adsorbent (Kantarli \& Yanik, 2009; Puchana-Rosera et al., 2015).

\section{Materials and Methods}

The raw tannery sludge was obtained from a tannery effluent treatment plant comprising of 76 tanneries in Ranipet located in the northern part of Tamilnadu, India. AR grade chemicals of Sigma Alrdrich and double distilled water were used for solution and sample preparation in this study. The collected sludge was dried in an oven at $80^{\circ} \mathrm{C} \pm 5^{\circ} \mathrm{C}$ and segregated for different particle gradation. Particle sizes of $600 \mu \mathrm{m}$ and $300 \mu \mathrm{m}$ were considered for further characterization in the development of activated carbon. Sulphuric acid under different proportions was used as chemical activating agent under an impregnation ratio of 1:1 and 5:1 (volume of acid to sludge ratio) for an impregnation period of 12 hrs. The prepared tannery sludge samples were used for the further thermal decomposition under controlled inert atmospheric condition at $650^{\circ} \mathrm{C}$ for $3 \mathrm{hrs}$.

Table 1. Characterization of the combined activation of tannery sludge carbon

\begin{tabular}{c|c|c|c}
\hline $\begin{array}{c}\text { Carbon } \\
\text { samples }\end{array}$ & Carbon, $\%$ & Carbon samples & Carbon, \% \\
\hline $6 S-11$ & 61 & $3 S-11$ & 63 \\
\hline $6 S-12$ & 62 & $3 S-12$ & 64 \\
\hline $6 S-21$ & 65 & $3 S-21$ & 64 \\
\hline $6 S-22$ & 70 & $3 S-22$ & 69 \\
\hline $6 S-51$ & 70 & $3 S-51$ & 74 \\
\hline
\end{tabular}

The surface morphology for the tannery sludge and the developed sludge carbons was analyzed using Scanning Electron Microscopy (SEM) of model and make JEOL JSM -6360. The surface area analysis, pore volume and pore size distribution were analyzed using multipoint adsorption/desorption, Brunauer Emmett and Teller isotherms. Horvath-Kawazoe (HK) method was adapted in evaluating the pore size distribution. 


\section{Results and Discussion}

\section{Characterization of tannery sludge activated carbon}

The tannery sludge carbons developed under different optimized conditions were characterized for the carbon percentage and are shown in Table 1. Sludge carbon developed from particle size $300 \mu \mathrm{m}$ had a higher carbon yield percentage of $74 \%$ at an impregnation ratio of 2 . The developed tannery sludge activated carbon was further analyzed for proximate and ultimate analysis and the results are represented in Table 2 and Table 3. The pH of the samples prepared were found to be ranging around $7.2 \pm 0.35$. Duration of activation and impregnation ratio are the significant variables that have major effects on the development of the porous network characterized in the activated carbon. There was an increase in the surface area that was observed by Vernersson et al. (2002) in their study with the Arundo canes from $38 \mathrm{~m}^{2} / \mathrm{g}$ to $1151 \mathrm{~m}^{2} / \mathrm{g}$, using ortho phosphoric acid as a chemical activating agent.

Table 2. Proximate analysis of the combined activation of tannery sludge carbon

\begin{tabular}{c|c|c|c|c|c}
\hline Activated carbon & Moisture content, $\%$ & Organic content, $\%$ & Ash content, $\%$ & Fixed carbon content, $\%$ & lodine number \\
\hline Sludge & $3.6 \pm 0.02$ & $32.5 \pm 0.03$ & $28.36 \pm 0.02$ & $35.54 \pm 0.03$ & $129.5 \pm 0.50$ \\
\hline $6 S-11$ & $2.55 \pm 0.15$ & $31.50 \pm 0.17$ & $26.35 \pm 0.35$ & $37.06 \pm 0.21$ & $278.7 \pm 0.70$ \\
\hline $6 S-12$ & $2.70 \pm 0.00$ & $31.46 \pm 0.00$ & $24.35 \pm 0.05$ & $38.80 \pm 0.05$ & $257.5 \pm 0.50$ \\
\hline $6 S-21$ & $2.35 \pm 0.05$ & $31.25 \pm 0.04$ & $23.75 \pm 0.05$ & $40.31 \pm 0.00$ & $279.0 \pm 0.00$ \\
\hline $6 S-22$ & $2.87 \pm 0.07$ & $30.54 \pm 0.08$ & $20.65 \pm 0.05$ & $43.08 \pm 0.00$ & $151.2 \pm 1.20$ \\
\hline $6 S-51$ & $2.80 \pm 0.10$ & $31.32 \pm 0.10$ & $17.20 \pm 0.00$ & $45.88 \pm 0.10$ & $253.5 \pm 0.50$ \\
\hline $6 S-52$ & $2.10 \pm 0.00$ & $32.15 \pm 0.05$ & $14.25 \pm 0.05$ & $49.40 \pm 0.00$ & $253.5 \pm 0.50$ \\
\hline $3 S-11$ & $2.10 \pm 0.02$ & $34.72 \pm 0.02$ & $25.70 \pm 0.10$ & $35.42 \pm 0.09$ & $296.5 \pm 0.50$ \\
\hline $3 S-12$ & $2.80 \pm 0.08$ & $33.42 \pm 0.09$ & $23.10 \pm 0.10$ & $37.83 \pm 0.04$ & $268.5 \pm 0.50$ \\
\hline $3 S-21$ & $2.20 \pm 0.05$ & $34.00 \pm 0.06$ & $22.20 \pm 0.20$ & $39.50 \pm 0.16$ & $36.5 \pm$ \\
\hline $3 S-22$ & $2.1 \pm 0.10$ & $34.13 \pm 0.10$ & $21.30 \pm 0.30$ & $40.37 \pm 0.40$ & 36.50 \\
\hline $3 S-51$ & $2.30 \pm 0.10$ & $33.65 \pm 0.08$ & $18.40 \pm 0.20$ & $43.36 \pm 0.09$ & $298.0 \pm 0.00$ \\
\hline $35-52$ & $2.4 \pm 0.25$ & $33.60 \pm 0.25$ & $15.60 \pm 0.20$ & $46.10 \pm 0.45$ & $377.5 \pm 0.50$ \\
\hline
\end{tabular}

Table 3. Ultimate analysis of the combined activation of tannery sludge carbon

\begin{tabular}{c|c|c|c}
\hline Material & C & H & N \\
\hline Raw sludge & 36.77 & 3.79 & 3.54 \\
\hline 6S-52 & 41.9 & 1.24 & 1.08 \\
\hline 3S-52 & 43.07 & 0.97 & 1.12 \\
\hline
\end{tabular}

12 different activated samples were prepared under various combinations of sludge particle size, dilution and acid to sludge impregnation ratio. Further pore size and volume analysis were determined for one sample each of $600 \mu \mathrm{m}$ and $300 \mu \mathrm{m}$ at 5:1 impregnation ratio (6S-52, 3S-52). The activated carbons with higher volatile content and lower ash content are the key requirements for an effective adsorbent (Jalel Ben et al., 2017). The volatile content and ash content of 3S-52 > 6S-52 but the carbon 
content of 3S-52 and 6S-52 was $46.10 \% \pm 0.45 \%$ and $49.40 \% \pm 0.20 \%$, respectively. Hence the carbon content increased with increasing particle size of the prepared activated carbon.

\section{SEM Analysis}

The SEM images revealed the formation of pores throughout the surface area of the developed activated carbons 6S-652 and 3S-52 during the activation process. The release of the volatile matter was due to the reaction between the chemical activating agent and the raw sludge precursor. The sludge carbon morphology has clearly depicted the pore development (Fig. 1a \& Fig. 1b), thereby confirming the sludge carbon as a potential adsorbent. The active sites of the tannery sludge developed activated carbon are clearly shown in Fig. 1a \& Fig. 1b. The efficiency of the adsorbent in the removal of reactive dyes in favoring adsorption process is discussed in the previous studies (Geethakarthi \& Phanikumar, 2012).

\section{Surface area analysis}

The efficiency and adsorption capacity of a pyrolyzed activated carbon are determined by the development of the surface area analysis including the pore volume and pore size distribution. The pore development analyzed for the prepared tannery sludge activated carbons was run by BET adsorption/desorption isotherm and is shown in Table 4. Figs. 3 and 4 represent the micropore distribution and pore size analysis of tannery sludge carbon (3S-52) carried out by $\mathrm{HK}$ desorption curve.

A very simple and popular method for evaluating the pore size distribution of microporous materials was proposed by Horvath and Kawazoe (1983). The pore distribution of the developed sludge activated carbon showed the dominance of the micropores in the sludge carbon (Fig. $2 \&$ Fig. 3). Though the pore surface area of the sludge carbon (3S-52) is lower than the commercial activated carbon (Table 4), the pore width has proven the acid impregnated tannery sludge activated carbon to give better results to be an effective and efficient adsorbent.

Fig. 1a, Fig. 1b. Scanning Electron Micrographs of activated tannery sludge carbon 6S-652 and 3S-52 prepared at an optimum temperature of $6500 \mathrm{C}$ with pore size of $10 \mu \mathrm{m}$ range at a magnification of $5 \times 1000$
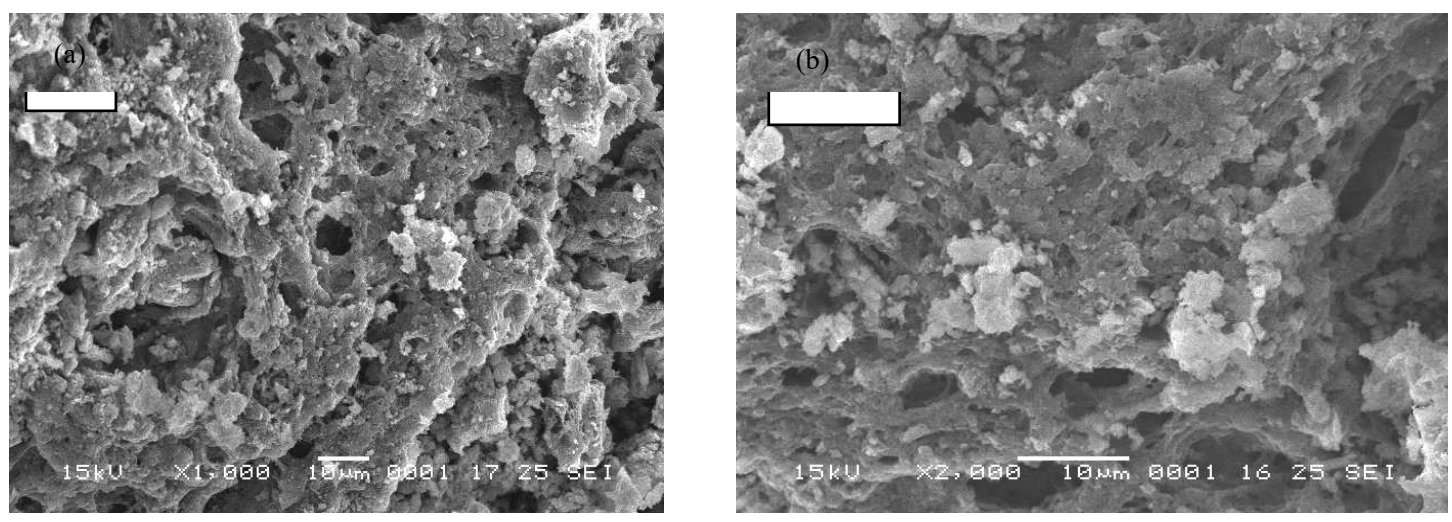

Table 4. Porosity characterization of the combined activation of tannery sludge carbon

\begin{tabular}{c|c|c|c}
\hline Carbon samples & Pore surface area $\left(\mathrm{m}^{2} / \mathrm{g}\right)$ & Pore volume distribution $\left(\mathrm{cm}^{3} / \mathrm{g}\right)$ & Pore width $\left(\mathrm{A}^{\circ}\right)$ \\
\hline Commercial activated carbon & 693.35 & 0.380042 & 5.25 \\
\hline 6S-52 & 188.25 & 0.132500 & 5.07 \\
\hline 3S-52 & 212.32 & 0.134239 & 5.15 \\
\hline
\end{tabular}


Fig. 2. BET isothermal adsorption desorption linear plot of tannery sludge activated carbon (3S-52) at $-196^{\circ} \mathrm{C} / 77 \mathrm{~K}, \mathrm{~N}_{2}$ atmosphere

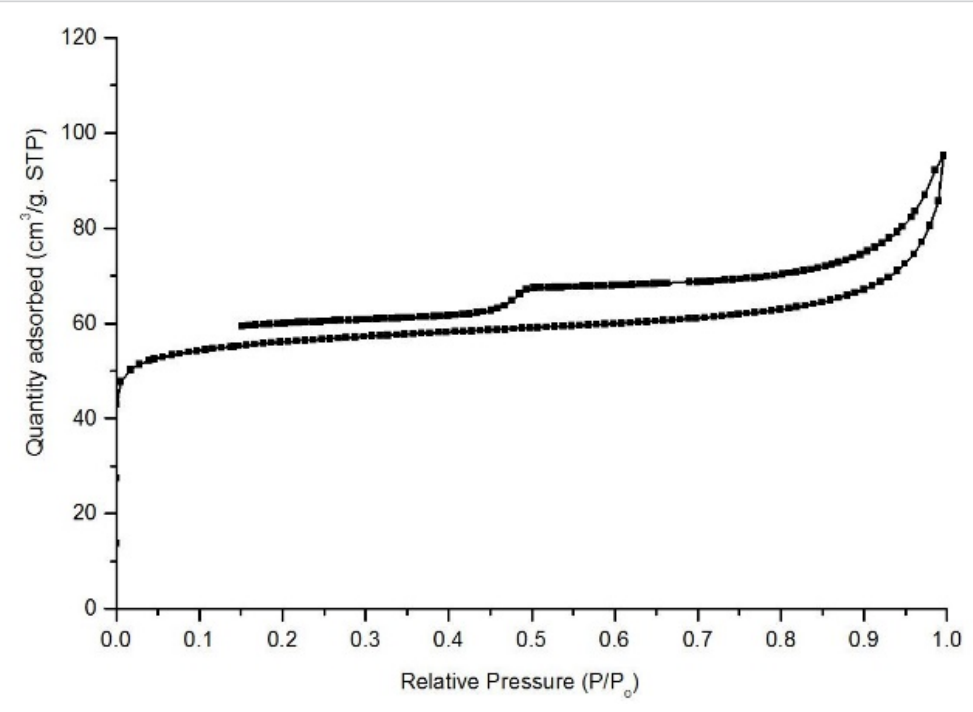

Fig. 3. Pore distribution of tannery sludge carbon (3S-52) by adsorption/desorption characterization of BET isotherm

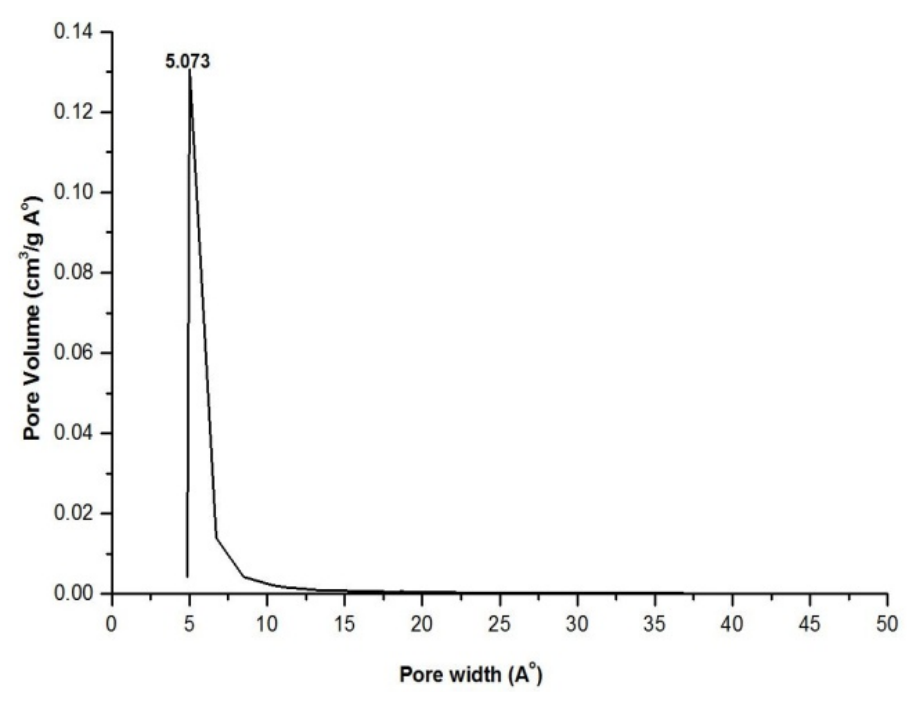

\section{Conclusions}

The development of an unused waste resource, raw tannery sludge, into effective activated carbon has yielded a carbon content of $74 \%$. The higher carbon yield was due to activation of the sludge using strong acid as the activating agent. The combined activation of the tannery sludge resulted in the formation of activated carbon at an optimum thermal condition of $650^{\circ} \mathrm{C}$ for $3 \mathrm{hrs}$. The surface morphology studies of the tannery sludge derived activated carbons confirmed the pore formation compared with the non-porous raw tannery sludge. The surface area and pore size were higher for the $300 \mu \mathrm{m}$ sludge sample (3S-52) and were found to be $212 \mathrm{~m}^{2} / \mathrm{g}$ and $5.15 \mathrm{~A}^{\circ}$, respectively. 


\section{Acknowledgements}

The author renders her sincere thanks to the Department of Science and Technology (DST), Government of India, for their financial support for carrying out this project.
This work was sanctioned under the reference number SR/WOS - A/ET-28/2007, with a funding of Rs. 16,16,000 for a project tenure of 3 years.

\section{References}

Anna Ros, M., Angeles Lillo-Rodenas., Carla Canals-Batlle., Enrique Fuente., Miguel A., Montes-Moran., Maria J. Martin., and Angel Linares-Solano (2007). A New Generation of Sludge-Based Adsorbents for H2S Abatement at Room Temperature. Environ. Sci. Technology.41: 4375 - 4381. https://doi.org/10.1021/es062358m

Geethakarthi, A., Phanikumar, B.R.(2012). Characterization of tannery sludge activated carbon and its utilization in the removal of azo reactive dye. Environ. Sci. Poll. Research. 19: 656-665. https://doi.org/10.1007/s11356-011-0608-z

Kantarli I C,Yanik J. Use of Waste Sludge from the Tannery Industry. Energy \& Fuels, 2009, 23(6): 3126-3133 https://doi. org/10.1021/ef8011068

Jalel Ben Nasr. Noureddine Hamdi and Foued Elhalouani (2017). Characterization of activated carbon Prepared from sludge paper for methylene blue adsorption. Journal of Materials and Environmental Sciences. 8: 1960 - 1967.

Li F, Yan B, Zhang Y, et al. Effect of activator on the structure and desulphurization efficiency of sludge-activated carbon. Environ- mental Technology, 2014, 35(17-20): 2575 https://doi.org/10.1 080/21622515.2014.913689

Puchana-Rosero, M.J.; Adebayo, M.A.; Lima, E.C.; Machado, F.M.; Thue, P.S.; Vaghetti, J.C.P.; Umpierres, C.S.; Gutterres, M. Microwave-assisted activated carbon obtained from the sludge of tannery-treatment effluent plant for removal of leather dyes. Colloids Surfaces A Physicochem. Eng. Asp. 2016, 504, 105-115 https://doi.org/10.1016/j.colsurfa.2016.05.059

Tiecheng Guo, Sicong Yao, Hengli Chen, Xin Yu, Meicheng Wang and Yao Chen (2017). Characteristics and adsorption study of the activated carbon derived from municipal sewage sludge. Water Science and Technology. 76: 1697 - 1705. https://doi. org/10.2166/wst.2017.352

Vernersson T. Bonelli PR. Cerrella EG and Cukierman AL (2002). Arundo donax cane as a precursor for activated carbon preparation by phosphoric acid activation. Bioresource Technology. 83: 95 - 104. https://doi.org/10.1016/S09608524(01)00205-X 